\title{
Antituberculosis Drug-induced Hepatotoxicity in Pediatric Tuberculosis
}

\author{
Vycke Yunivita, ${ }^{1}$ Muhammad Iqbal, ${ }^{2}$ Adi Utomo Suardi ${ }^{3}$ \\ ${ }^{1}$ Department of Biomedical Sciences Faculty of Medicine Universitas Padjadjaran, Indonesia, \\ ${ }^{2}$ Faculty of Medicine Universitas Padjadjaran, Indonesia, ${ }^{3}$ Department of Child Health Faculty of \\ Medicine Universitas Padjadjaran/Dr. Hasan Sadikin General Hospital Bandung, Indonesia
}

\section{Abstract}

Background: Hepatotoxicity is the most serious side effect caused by using oral antituberculosis (OAT) drugs. This study was performed to determine the characteristics of patients who had antituberculosis drug-induced hepatotoxicity (ADIH) among pediatric inpatient with pulmonary tuberculosis.

Methods: This was a cross-sectional study with a total sampling of medical records taken from January-December 2012, including pediatric pulmonary tuberculosis inpatients aged <14 years old at the Department of Child Health of Dr. Hasan Sadikin General Hospital Bandung. The inclusion criteria were children with pulmonary tuberculosis who received OAT drugs. Patients with liver disease were excluded. Data on alanine and aspartate aminotransferase were collected and an increased level of serum aminotransferase was designated as hepatotoxicity.

Results: In total, 86 medical records were obtained of whom 24 had ADIH, predominantly occurred in girls (71\%), aged 5-9 years old (42\%) and in the intensive phase of therapy (58\%). Elevated serum alanine aminotransferase (58\%), aspartate aminotransferase (92\%), and bilirubin (0.8\%) were found. Malnutrition (46\%) was common. The difference indeviation of liver function was statistically significant $(\mathrm{p}<000)$ between subjects with and without ADIH.

Conclusions: Hepatotoxicity is most prominent in patients with malnutrition, girls aged 5-9 years old and in the intensive phase of therapy. Children with malnutrition during antituberculosis therapy are suggested to have a periodic liver function test monitoring to prevent the development of ADIH.

Keywords: Antituberculosis, children, hepatotoxicity, tuberculosis

\section{Introduction}

Indonesia is a country rich in natural resources Tuberculosis (TB) remains a major health problem in the world. The World Health Organization (WHO) has predicted that there might be 10 million TB cases in 2017 of whom $64 \%$ are new cases. More than one million of TBpatients are children and nearly one hundred thousand TB death are among HIV-negative children. Indonesia is the ninth country with the largest incident of TB cases in 2017.1

The basic principle in TB therapy is oral antituberculosis (OAT) drugs, consisting of four drugs regimen including isoniazid (INH), rifampicin (RIF), pyrazinamide (PZA) and ethambutol (EMB) for positive acid-fast bacilli (AFB). For negative AFB children in the intensive phase i.e. the first 2 months have been given otherwise three drugs regimen without EMB. Furthermore, during the maintenance phase or in the next 4 months of TB treatment, two drugs (RIF and INH) have been given. Morevoer, good nutrition must be monitored and comorbidities need to be checked thoroughly. ${ }^{2}$ Antituberculosis druginduced hepatotoxicity $(\mathrm{ADIH})$ is the most frequent side effect of OAT drugs. ${ }^{3}$ The mild or moderate clinical symptoms of ADIH are jaundice and gastrointestinal problems, such as loss of appetite, nausea, confusion, vomiting, and abdominal pain. This side effect may influence patient compliance's and determine the outcome of therapy. ${ }^{4}$ Many studies have investigated clinical parameters ADIH in adult subjects. ${ }^{5-7}$ In contrast, signs or symptoms of ADIH are often ignored in pediatric TB. ${ }^{8}$ Therefore, it is necessary to identify the incidence and characteristics of OAT drugs side 
effects' in children. This study intended to find the incidence and characteristic of children with pulmonary TB who had hepatotoxicity due to OAT drugs.

\section{Methods}

This was an observational analytic study with a cross-sectional approach, conducted in Dr. Hasan Sadikin General Hospital Bandung. Data werecollected from inpatient's medical records with a total sampling method. The pulmonary TB in children was diagnosed based on the TB scoring system. The inclusion criteria were data of pediatric inpatient aged $<14$ years old, that was diagnosed to have pulmonary TB and received OAT drugs, and that was admitted in the ward during JanuaryDecember 2012. Patients with liver disease were excluded. The data were recorded such as age, gender, phase of TB treatment and other diseases or comorbidities that were existed in those patients. The study was approved by the Health Research Ethics Committee, Faculty of Medicine, UniversitasPadjadjaran.

The ADIH was marked by the deviation of normal liver function test (LFT) including alanine aminotransferase (ALT), aspartate aminotransferase (AST), and bilirubin. Furthermore, clinical symptoms of liver dysfunction such as jaundice might also be present during antituberculosis treatment. ${ }^{8}$ Grade 1 was designated when ALT or AST was increased up to 3 times from upper normal limit or increased 1.5-3 times from baseline if the baseline was abnormal; or when bilirubin was increased up to 1.5 times from upper normal limit or increase 1-1.5 times from baseline if the baseline was abnormal. Grade 2 was designated when transferases was increased $>3-5$ times from upper normal limit or baseline if the baseline was abnormal; or when bilirubin was increased $>1.5-3$ times from upper normal limit or baseline if the

Table 1 The Characteristics of Children with Pulmonary Tuberculosis, Admitted in Dr. Hasan Sadikin General Hospital from January to December 2012.

\begin{tabular}{|c|c|c|c|c|c|}
\hline Characteristic & $\begin{array}{l}\text { With ADIH } \\
(n=24) \\
\end{array}$ & $\%$ & $\begin{array}{l}\text { Without } \\
\text { ADIH } \\
(n=62)\end{array}$ & $\%$ & $\mathbf{p}$ \\
\hline Age, years & & & & & $0.215^{\mathrm{a}}$ \\
\hline $0-4$ & 8 & 33 & 36 & 58 & \\
\hline $5-9$ & 10 & 42 & 17 & 27 & \\
\hline $10-14$ & 6 & 25 & 9 & 15 & \\
\hline Gender & & & & & $0.221^{\mathrm{b}}$ \\
\hline Boys & 7 & 29 & 27 & 43 & \\
\hline Girls & 17 & 71 & 35 & 57 & \\
\hline Number of comorbidities & & & & & $0.950^{\mathrm{b}}$ \\
\hline 0 & - & - & 1 & 2 & \\
\hline 1 & 8 & 33 & 24 & 39 & \\
\hline 2 & 8 & 33 & 17 & 27 & \\
\hline 3 & 6 & 25 & 11 & 18 & \\
\hline 4 & 2 & 8 & 5 & 8 & \\
\hline$>4$ & - & - & 4 & 6 & \\
\hline Phase of TB treatment & & & & & $0.848^{\mathrm{b}}$ \\
\hline Intensive & 14 & 58 & 36 & 58 & \\
\hline Maintenance & 9 & 38 & 21 & 34 & \\
\hline Not identified & 1 & 4 & 5 & 8 & \\
\hline
\end{tabular}


baseline was abnormal. Grade 3 was designated when transferases were increased $>5-20$ times from upper normal limit or baseline if the baseline was abnormal; or when bilirubin was increased $>3-10$ times from upper normal limit or baseline if the baseline was abnormal. Grade 4 was designated when transferases were increased $>20$ times from upper normal limit or baseline if the baseline was abnormal, or when bilirubin was increased $>10$ times from upper normal limit or baseline if the baseline was abnormal. ${ }^{9}$

The data weregrouped into ADIH cases and control was a group without ADIH. The characteristic between groups wascompared and analyzed using the independent t-test for variable numerical or independent samples Mann-Whitney U test when the data werenot normally distributed. As for the categorical variable, the Chi-Squares test was performed. Statistically significant was considered when $\mathrm{p}<0,05$. Analysis was conducted using SPSS version 22 (spss.license.unpad.ac.id).

\section{Results}

During January-December 2012, there were 86 children with pulmonary TB were included in this study, of whom only 24 subjects were reported to have ADIH. Most of the children with ADIH were girls (71\%), aged 5-9 years old $(42 \%)$ with two or three comorbidities (33\%), and they were in the intensive phase of therapy (58\%), as depicted in Table 1 . There were no significant statistical differences between the group with ADIH and without $\mathrm{ADIH}$. Interestingly, the malnutrition was more often in ADIH cases (46\%) compared to those without ADIH (29\%).

In a subset of the children (n36) of whom ALT, AST and bilirubin were examined; there were $24(67 \%)$ subjects who were indicated

Table 2 The Median Concentration and Distribution of the Liver Function Test Result and Clinical Symptoms

\begin{tabular}{|c|c|c|c|}
\hline Parameter & $\begin{array}{c}\text { With ADIH } \\
\begin{array}{c}\text { n (\%) } \\
\text { n=24 }\end{array}\end{array}$ & $\begin{array}{c}\text { Without ADIH } \\
\begin{array}{c}\text { n (\%) } \\
\text { n=12 }\end{array}\end{array}$ & $\mathbf{p}$ \\
\hline ALT, u/L; median (range) & $49.5(8-728)$ & $10(7-24)$ & $0.000^{\mathrm{a}}$ \\
\hline Normal & $10(42)$ & $12(100)$ & \\
\hline Grade1 & $6(25)$ & - & \\
\hline Grade 2 & $3(13)$ & - & \\
\hline Grade 3 & $5(21)$ & - & \\
\hline Grade 4 & - & - & \\
\hline AST, u/L; median (range) & 83 (24-997) & $28(16-41)$ & $0.000^{\mathrm{a}}$ \\
\hline Normal & $2(8)$ & $12(100)$ & \\
\hline Grade1 & $16(67)$ & - & \\
\hline Grade 2 & $1(4)$ & - & \\
\hline Grade 3 & $4(17)$ & - & \\
\hline Grade 4 & $1(4)$ & - & \\
\hline Bilirubin, mg/dL; median (range) & & NA & NA \\
\hline Normal & $1(33)$ & & \\
\hline Grade1 & $1(33)$ & & \\
\hline Grade 2 & - & & \\
\hline Grade 3 & - & & \\
\hline Grade 4 & $1(33)$ & & \\
\hline
\end{tabular}

Note: Data are in $\mathrm{n}(\%)$ or median (range); ALT=alanine aminotransferase; AST=aspartate aminotransferase; NA=Data

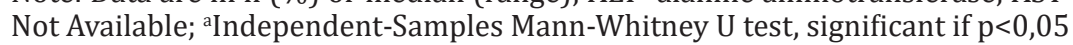


ADIH and 12 (33\%) were not ADIH. Grade 4 ADIH occurred in 2 of 24 cases (8\%) from the measurement of AST and bilirubin levels. The ALT and AST levels of the subject who had jaundice were in grade 2 , respectively. There wasa significant difference $(p<0,05)$ deviation of normal LFT based on ALT or AST levels between subjects with and without ADIH. However, only 1 patient had jaundice (Table 2).

\section{Discussions}

The ADIH in our study has been found in $28 \%$ (24/86) children; however, the laboratory examination was only conducted in 36 children; thus ADIH with confirmed laboratory test was $67 \%$, suggesting that laboratory examination is needed in pediatric TB. In previous study, ADIH in hospital has reached $45 \%, 10$ whereas first publication about the disturbance of LFT on subjects pulmonary TB who was administered RIF and INH just 13/37 (35\%) subjects. ${ }^{8}$ The incidence of ADIH in children is higher than in adults who received RIF and INH. The high frequency of ADIH in pediatric pulmonary TB has been reported in $25-52 \%$ of all patients. ${ }^{11}$ Therefore, laboratory examination for the liver function is necessary to confirm the ADIH status. Interestingly, although there is a state of ADIH, only 1 child has shown jaundice as a sign of ADIH with LFT elevation. The ADIH symptoms in the children are less than the adults; it may be due to the incidence of ADIH in children is less frequent than in adults receiving comparable drug dosages and regimens. Study comparing 56 children $<19$ years of age and 213 adults with OAT drugs and liver enzymes measurements that have been taken routinely at two, four, six and eight weeks after treatment start, shows that no children have more than grade 3 of ADIH and none with signs or symptoms of ADIH; whereas 20 adults (9.4\%) have ADIH. ${ }^{8}$

ADIH formation has occurred in a complex process that involves a direct pathway, degree of liver injury and its outcome. The key upstream events are triggered by particular drugs or theirmetabolites, which may induce hepatotoxicity. This event is initiated by the increased reactivity of metabolite formation, which is generally a result of phase 1 metabolism, or failure in the metabolic detoxification functions of phase 2. The expression of the enzymes that metabolize the drugs and transporter in the process of excretion and elimination of drugs metabolites (phase 3) have been regulated by transcription factors. Genetic and environmental factors that may affect the expressions and activities of proteins in phases $1,2,3$ of drug metabolism would affect the rate of the formation and accumulation of reactive metabolites. These reactive metabolites would induce an excessive reactive oxygen species (ROS) formation that makes lipid peroxidation and cell death, causing hepatocellular damage. This hepatocellular damage causes a release of ALT and AST into the bloodstream, resulting in an increased in ALT levels. Moreover, there is also an elevation of bilirubin levels in hepatocellular damage, making the trias or three measurements of ALT, AST, and bilirubin as specific biomarkers to hepatocellular damage induced by OAT. ${ }^{12}$

Our study involved forty percent of children aged 5-9 years old with ADIH. The previous study has found that the majority children with ADIH are below the age of 5 years old. ADIH can occur in children at any age, although the risk of complication is increased in the younger age $<4$ years of age, however, the incidence of $\mathrm{ADIH}$ is markedly lower in children than in adults. $8,10,13$

Interestingly, our study has shown that the ADIH waspredominantly in girls, although no association between gender and incidence ADIH in children. ${ }^{13}$ In the contrary, female adults are 4-fold more susceptible to ADIH than males, due to thehigh activity of CYP3A in the female. This enzyme oxidizes toxic isoniazid hydrazine, which is the result of isoniazid hydrolysis to N-hydroxy acetyl hydrazine; before further dehydrated to yield acetyl diazines. Acetyl-diazines could be degraded into toxic metabolites or acetyl onium ion, ketene, acetyl radicals that bind covalently to hepatic macromolecules, causing in turn into hepatocellular damage. ${ }^{11}$ Moreover, most of the children with ADIH in this study were in the intensive phase of therapy (56\%). Patients who had been received anti-tuberculosis drugs may have increased ALT or AST concentration within 12-60 days, ${ }^{5}$ and the development of ADIH may start during the first 2 weeks of drug administration. ${ }^{14}$

The comorbidities in children in our study have been described as bronchopneumonia, malnutrition, sepsis, nephropathy, meningoencephalitis and many others; of which malnutrition $(46 \%)$ is the most common. Malnutrition is associated with a higher incidence of $\mathrm{ADIH},{ }^{15}$ and considered as one of the factors contributing to a higher incidence of ADIH due to inadequate intake of important nutrients in maintaining the integrity of liver metabolism and detoxification of anti- 
tuberculosis drug in malnourished states. ${ }^{11}$

Some limitations encountered in this study were various comorbidities that may influence the patient's condition and liver function test, leading to eventually confounding results. The deviation of normal LFT should be checked for every patient who received antituberculosis drugs to manage pulmonary TB effectively. Genetic tests related to susceptibility to druginduced hepatotoxicity might be a topic of interest.

In conclusion, antituberculosis druginduced hepatotoxicity (ADIH) has been diagnosed based on the elevation of ALT, AST, and bilirubin; with malnutrition as the most common comorbidities. Children with malnutrition during antituberculosis therapy are suggested to have a periodic liver function test monitoring to prevent the development of ADIH.

\section{References}

1. World Health Organization. Global tuberculosis report 2018. Geneva: World Health Organization; 2018.

2. Direktorat Jenderal Pencegahan dan Pengendalian Penyakit Kementerian Kesehatan Republik Indonesia. Petunjuk teknis manajemen dan tatalaksana TB anak. Jakarta: Kementerian Kesehatan Republik Indonesia; 2016. p. 1-84.

3. Babalik A, Arda H, Bakirci N, Ağca S, Oruç $\mathrm{K}$, Kiziltaş Ş, et al. Management of and risk factors related to hepatotoxicity during tuberculosis treatment. Tuberk Toraks. 2012;60(2):136-44.

4. Bagiada IM, Primasari NLP. Faktorfaktor yang mempengaruhi tingkat ketidakpatuhan penderita tuberkulosis dalam berobat di poliklinik DOTS RSUP Sanglah Denpasar. J Peny Dalam. 2010;11(3):158-63.

5. Faiz SN, Chowdhury N, Khan MAH, Parvin R. Evaluation of risk factors for hepatotoxicity in patients receiving antitubercular four drugs regimen in initial two months. Chattagram Maa-O-Shishu Hosp Med Coll

\section{J. 2015;14(1):15-8.}

6. Dianwari V, Yunivita V, Kania N. Effect of nti-tuberculosis drugs on liver damage based on alanine aminotransferase level in pulmonary tuberculosis patients. Althea Medical Journal. 2017;4(4):506-11.

7. Sun $\mathrm{Q}$, Zhang $\mathrm{Q}, \mathrm{Gu} J$, Sun $\mathrm{W}$, Wang $\mathrm{P}$, Bai C, et al. Prevalence, risk factors, management, and treatment outcomes of first-line antituberculous druginduced liver injury: a prospective cohort study. Pharmacoepidemiol Drug Saf. 2016;25(8):908-17.

8. Donald PR. Antituberculosis drug-induced hepatotoxicity in children. Pediatr Rep. 2011;3(2):e16.

9. US Department of Health and Human Service. Common Terminology Criteria for Adverse Events (CTCAE) v5.0. Washington: National Institute of Health; 2017. p. 1-152.

10. Nataprawira HM, Hannah RA, Kartika HH. Hospitalized pediatric antituberculosis drug induced hepatotoxicity: Experience of an Indonesian referral hospital. Asian Pacific J Trop Dis. 2017;7(5):276-9.

11. Ramappa V, Aithal GP. Hepatotoxicity related to anti-tuberculosis drugs: mechanisms and management. J Clin Exp Hepatol. 2013;3(1):37-49.

12. Oh RC, Hustead TR. Causes and evaluation of mildly elevated liver transaminase levels. Am Fam Physician. 2011;84(9):1003-8.

13. Mansukhani S, Shah I. Hepatic dysfunction in children with tuberculosis on treatment with antituberculous therapy. Ann Hepatol. 2012;11(1):96-9.

14. Singanayagam A, Sridhar S, Dhariwal J, Abdel-Aziz D, Munro K, Connell DW, et al. A comparison between two strategies for monitoring hepatic function during antituberculous therapy. Am J Respir Crit Care Med. 2012;185(6):653-9.

15. Singla R, Sharma SK, Mohan A, Makharia G, Sreenivas V, Jha B, et al. Evaluation of risk factors for antituberculosis treatment induced hepatotoxicity. Indian J Med Res. 2010;132:81-6. 


\section{Index Althea Medical Journal}

Author Index 
Subject Index 